\title{
REFINEMENTS TO THE EFDC MODEL FOR PREDICTING THE HYDRO- ENVIRONMENTAL IMPACTS OF A BARRAGE ACROSS THE SEVERN ESTUARY
}

\author{
JUNTAO ZHOU (1), ROGER A. FALCONER (1), BINLIANG LIN (1, 2) \\ (1): Hydro-environmental Research Centre, School of Engineering, Cardiff University, Cardiff CF24 \\ $3 A A, U K$ \\ (2): State Key Laboratory of Hydroscience and Engineering, Tsinghua University, Beijing 100084, \\ China
}

\section{ABSTRACT}

This paper presents an investigation of the impacts of a Severn Barrage on the hydro-environment of the Bristol Channel and Severn Estuary using the Environmental Fluid Dynamics Code (EFDC) model with a recently developed Barrage module (EFDC_B). Details are given of a barrage module being implemented into the EFDC model to represent the various hydraulic structures, such as turbines and sluice gates, as deployed along the barrage line. Several cases, both with and without the barrage, have been simulated to investigate the potential changes on the peak water levels, minimum water depths and peak tidal currents arising from a barrage. The impacts of a barrage on the salinity concentration distribution have also been simulated in both 2D and 3D modes. The predicted results showed that the maximum water levels could be significantly reduced, especially downstream of the barrage and for much of the region in the Severn Estuary and that the minimum water depths would be changed so much that there would be $80.5 \mathrm{~km}^{2}$ loss of intertidal habitats due to the sitting of a barrage across the estuary. Likewise, the peak tidal currents would be considerably reduced, and by as much as a half in the middle of the main channel. The predicted salinity concentrations results indicated that at high water, the salinity concentrations would be reduced by 1-2 ppt downstream and upstream of the barrage and salinity concentrations in the region near Beachley would be reduced by up to 5 ppt, and that at low water, salinity concentrations would be reduced by 0.5 - 1 ppt in the middle of the Bristol Channel and by typically 0.5 ppt and 1 ppt downstream and upstream of the barrage, respectively. The predicted results also indicated that salinity concentrations downstream and upstream of the barrage would be under a stable state with slight oscillations all the time due to the effects of the barrage. A comparison between the salinity concentration distributions predicted by the 2D and 3D models indicated that the 
two models produced similar salinity distributions, especially in the Severn Estuary and in the region between the middle of the Bristol Channel and the seaward open boundary.

KEY WORDS: Tidal Barrage; Numerical modelling; EFDC_B model; Hydrodynamics; Salinity; Tidal Power; 3D effects

\section{INTRODUTION}

Over the past few decades, the energy demand has been continuously increasing as a result of developing economies, particularly in China and India, and population growth. On the other hand, due to the over-dependence on traditional energy sources (such as fossil fuels and natural gas), global reserves are quickly depleting and hence the price of traditional energy has increased significantly. Compared with traditional energy resources, renewable energy resources have many advantages, such that increasing efforts are now being made to increase the provision of such resources. Among the range of renewable resources available, tidal power has great potential for future electricity generation, since tides are predictable compared to wind energy, solar power etc. (Falconer et al. [1]).

With one of the highest tidal ranges in the world occurring in the Bristol Channel and Severn Estuary, located in the southwest of the UK (see Fig. 1), this basin is regarded as an ideal location for potential tidal energy extraction. Therefore, it is significant to predict numerically the effects of a tidal barrage on the hydro-environment of the Bristol Channel and Severn Estuary. Recently, several numerical models have been used to study the tidal hydrodynamic processes and tidal barrage impacts on the aquatic environment in the Severn Estuary. Owen [2] and Stephens [3] used 3D regular grid numerical models to predict tidal levels and currents in the Bristol Channel, with the horizontal grid size being over $1 \mathrm{~km}$. According to the observed current data from 1975 to 1977, Uncles and Jordan [4] derived co-phase and co-amplitude lines for the M2 tide and obtained estimates of the associated tidal energy fluxes through selected cross-sections. Evans et al. [5] investigated the effect of a barrage on the water quality parameters in the estuary using a depth-averaged 2D hydrodynamic model. In this study four types of nested grids of square cells were deployed to represent the topography, with the finest grid size being $0.167 \mathrm{~km}$ covering the proposed barrage site. Amin and Flather [6] dynamically linked a 2D numerical model of the Bristol Channel to a 1D model of the River Severn and compared the numerical model predicted water levels with the corresponding values predicted based on a harmonic analysis. 
1 More recently, Xia et al. [7, 8, 9] deployed a 2D finite volume numerical model to investigate the

2 impact of different tidal renewable energy schemes on the hydrodynamic processes. Due to the

3 advantages of an unstructured triangular mesh, as used in this model, the model accurately fitted the complex and irregular land boundary and especially around the barrage structure, with accurate simulations and predictions of the hydrodynamic processes in the region of the structure being achieved. However, one of the disadvantages of an unstructured grid is that it not only needs to generate a grid and to process and store the "connectivity” information, but also that every node has a different scattering behaviour, which incurs both a memory and speed penalty, especially if a 3D model is required. Ahmadian et al. [10] used a regular grid model, namely the DIVAST model, to investigate the hydrodynamic and corresponding suspended sediments and bacterial fluxes in the Bristol Channel and Severn Estuary. Good agreement between the predicted results and field data were obtained based on a fine grid distributed throughout the whole computational domain. Undoubtedly improvements in the accuracy were obtained at the expenses of computational efficiency in these numerical model simulations. Furthermore, as the Severn Estuary becomes very narrow and meanders upstream of the Severn Bridge, then computational efficiency is very low if the same 2D grid resolution is used along the estuary. To overcome this problem, a linked 1D-2D model was used, with the linked model being allowed to overlap for a distance to ensure numerical stability between the two models. The linked 1D2D model may yield an inconsistent problem of accuracy between the $1 \mathrm{D}$ and $2 \mathrm{D}$ models, which further affects the accuracy of an integrated model solution.

Hence, a curvilinear orthogonal grid model, namely EFDC, has been used and presented in this study. A curvilinear orthogonal mesh can accurately represent the complex coastline and estuarine boundaries, without the need for any model coupling and has the advantage of computational efficiency over unstructured grid models.

\section{DESCRIPTION OF EFDC MODEL}

The EFDC model [11] is a general purpose modelling package for simulating three-dimensional flow, transport, and biogeochemical processes in surface water systems, including: rivers, lakes, estuaries, reservoirs, wetlands and near-shore to shelf-scale coastal regions. The EFDC model can predict the water level and velocity, salinity and temperature distributions and also simulates the processes of cohesive and non-cohesive sediment transport, near field and far field discharge dilution 
1 from multiple sources, eutrophication, the transport and fate of toxic contaminants in the water and

2 sediment phases, and the transport and fate of various life stages of finfish and shellfish. EFDC also

3 allows for drying and wetting in shallow areas using a mass conservative scheme. A number of

4 alternatives are in place in the model to simulate general discharge control structures, such as weirs,

5 spillways and culverts. The model uses either stretched or sigma vertical coordinates and Cartesian or curvilinear orthogonal horizontal coordinates. Dynamically coupled transport equations for turbulent kinetic energy, turbulent length scale, salinity and temperature are also solved. The two turbulence parameter transport equations based on the Mellor-Yamada level 2.5 turbulence closure schemes are used [12]. A second-order accurate spatial finite difference formulation on a staggered (or C) grid is used to solve the momentum equations, while a second-order accurate three-time level finite difference scheme is used, with an internal-external mode splitting procedure adopted to separate the internal shear, or baroclinic mode, from the external free surface gravity wave, or barotropic mode. A numerical solution based on a second-order accurate scheme in both space and time, and a mass conservative fractional step algorithm is used to solve the transport equations for salinity, temperature and other constituents. More details of the governing equations for the original EFDC hydrodynamic model equations and the numerical schemes can be found in Hamrick, [11]. The EFDC model is a public domain software, and has been extensively tested and applied in more than 100 modelling studies worldwide. The model has been successfully applied to reservoirs and lakes [13], bays and estuaries [14], [15], [16] and [17] to study the hydrodynamic and water quality processes [18], tidal intrusion and sediment transport and its impact on the fate of faecal bacteria [19].

\section{BARRAGE MODULE DEVELOPED FOR EFDC MODEL}

In this study the main aim has been to assess numerically the impact of the Severn Barrage on the hydro-environment in the Severn Estuary and Bristol Channel. Hence a barrage module has been developed for inclusion within the EFDC model to represent the operation of a barrage. The numerical model EFDC with a barrage module can be abbreviated to EFDC_B model. There are two main types of devices frequently included in barrages for connecting the conditions upstream and downstream of the structure, i.e. sluice gates and turbines. The numerical implementation of a sluice gate is similar to the procedure that occurs in reality. When the sluice gates need to be closed, then the current velocities through the computational cells representing the sluice gates are set to gradually decrease to zero. 
1 Likewise when the sluice gates need opening, the velocities are set to gradually increase to the peak velocity. Hydraulic structures have been adopted to represent the turbines. In EFDC each hydraulic structure has an upstream end and a downstream end and water can only flow from upstream to downstream of the hydraulic structure, thus two hydraulic structures are required in order to simulate water passing through the barrage. The upstream and downstream conditions of the hydraulic structures have been linked dynamically using a $Q-H$ relationship. The discharge $Q$ through a turbine was obtained by linking $Q$ with the difference between the upstream and downstream water head as given by:

$$
Q=C_{d} A \sqrt{2 g H}
$$

where $C_{d}$ is the discharge coefficient of a turbine; $A$ is the area of the opening and $H$ is the head difference across the turbine. For the Severn Barrage Severn Tidal Power Group study [20] where the turbine diameter was assumed to be $9 \mathrm{~m}$, and the mean wet flow-through area of each turbine was 63.6 $\mathrm{m}^{2}$. The formula for computing the generation power of $P$ can be expressed by

$$
P=\rho g Q H \eta
$$

where $\rho$ is the specific density of sea water $\left(\mathrm{kg} / \mathrm{m}^{3}\right)$; and $\mathrm{Q}$ is the discharge across the turbines $\left(\mathrm{m}^{3} / \mathrm{s}\right)$; $\eta$ is the efficiency coefficient of the turbines and $g$ is gravitational acceleration. In the current study the discharge coefficient $C_{d}$ was assumed to be 1 for turbines and the efficiency coefficient $\eta$ was assumed to be $1[8]$ and [21].

The Severn Barrage scheme proposed by the Severn Tidal Power Group [20] would stretch nearly 16 km from Lavernock Point, southwest of Cardiff, to near Brean Down, near Weston-Super-Mare. This structure included 216 bulb turbines and 166 sluices, with a detailed layout of this barrage configuration being given in Fig 2. The energy operating scheme for this original Severn Barrage layout was designed as a one-way generation process [20], i.e. only ebb generation was considered suitable for this Barrage. Ebb generation usually has four stages, namely: filling, holding (i), generating and holding (ii), respectively. When the barrage is at the filling stage, the sea water flows through the 
sluices and turbines, raising the water level upstream of the barrage until high water level is reached and then the sluice gates and turbines are closed. For the holding stage (i): both the turbines and sluice gates are kept closed until there is sufficient head difference (i.e. the starting head) created between the downstream and upstream sides of the barrage due to the sea level fall; the turbines are then switched on to generate power until the head difference is lower than the minimum water head for turbine operation. At the last stage (i.e. the holding stage (ii)), both the turbines and sluice gates are closed again until the downstream sea level is greater than the basin level, and another filling stage then commences.

In order to obtain the same computational accuracy between the barrage and no-barrage cases, the same mesh has been used in the cases with and without a barrage except in the region of the barrage. Furthermore, for accurate simulations of the barrage operating scheme and the complex flow patterns around the barrage, a fine grid was deployed in the region surrounding the barrage with the total cell number being 53,914 for the case with the barrage and with the representative grid size around the barrage being $70 \mathrm{~m}$ x $100 \mathrm{~m}$. Fig. 3 shows the distribution of the fine grid and the corresponding device locations along the barrage line. In this study, the hydraulic structures such as the ship locks, substations and embankments along the barrage line were all treated as wall boundaries. Due to the instant opening and closing of the turbines and the sluice gates, some numerical oscillations in water elevations can be observed when the barrage is in operation. To remove these numerical oscillations, a ramp function was introduced to change the flow volume through the turbines and sluice gates during the opening and closing of turbines and sluice gates, as would occur in reality. Assuming that it takes a time period of $\mathrm{T}$, required to open the turbine valves (or sluice gates), the ramp function is $f=\sin \left(\frac{\pi}{2} \frac{t}{T}\right), 0<t \leq T$, where $T=10$ minutes in this study (based on typical opening times sited in commercial literature), and $t$ is time. When the turbine valves (or sluice gates) start to open, $t=0$ and $f=0$; when they are fully opened, $t=T$ and $f=1$. Likewise, when these hydraulic structures need closing, the ramp function is changed into $f=\cos \left(\frac{\pi}{2} \frac{t}{T}\right), 0<t \leq T$. Based on different operation procedures of the barrage and the head differences downstream and upstream of the barrage, these can be used to decide what time to open the turbine valves and sluice gates or to close them, and then the flow volumes through the turbines and sluice gates are gradually increased or decreased by multiplying the discharge by the ramp function. 


\section{MODEL DETAILS AND VALIDATION}

The bathymetry of the computational domain is shown in Fig. 4, where the elevation data are provided relative to the Ordnance Datum (OD). The total model area is about $5700 \mathrm{~km}^{2}$ which covers the whole of the Bristol Channel and the Severn Estuary. The western boundary, i.e. the open boundary, was set between Hartland point in England and Stackpole Head in Wales, with the time varying water level being specified along this boundary. The landward boundary was set at the River Severn tidal limit, located close to Gloucester, to account for the possible impact of the Severn Barrage on the tidal levels of the River Severn. The corresponding water level at the open boundary was specified using the predicted elevation data from POLPRED (Xia et al., 2010a). The simulation duration was 300 hours, starting from 5:30pm on $20^{\text {th }}$ July, 2001 to 5:30am $2^{\text {nd }}$ August, 2001 (excluding the salinity flux studies). The total CPU time for this case was 2.64 hours using a PC with Intel (R) Core (TM) 8 CPU @ 2.4 GHz (only one CPU was used) and 24G RAM. Only one river was considered in the fresh water inflow simulations in this study, namely the River Severn, as this was the most substantial river in terms of water flow into the basin from England and Wales. A constant base flow rate of $100 \mathrm{~m}^{3} / \mathrm{s}$ was used in this study, for the River Severn inflow boundary at Gloucester. It also can be seen from Fig. 4 that the gradient of seabed elevation is relatively steep, with the average bed elevation decreasing from about $-60 \mathrm{~m}$ near the open seaward boundary to about $-10 \mathrm{~m}$ near Avonmouth. Furthermore, the surface width also decreases greatly throughout the whole computational domain, from about $72 \mathrm{~km}$ at the open seaward boundary to about $130 \mathrm{~m}$ at the landward boundary at Gloucester. Because of the bell-mouthed shape of the estuary, the irregular land boundary and the high tidal range, it is always a challenge for any numerical model to obtain a stable and accurate simulation for this estuary. Comparisons between the field data and numerical results have been made in this section to illustrate that good agreement has been achieved using the EFDC model. Based on a sensitivity analysis of this model for different time steps, a constant time step of $5 \mathrm{~s}$ was chosen for the simulations.

\subsection{Validation of tidal level}

The model predicted water levels were first validated against the field data. Three typical sites were chosen for the comparisons, i.e. the Mumbles, Newport and the Hinkley Point, which are located 
upstream and downstream of the barrage site respectively, and with the last two sites being close to the barrage location. Comparisons of water levels for the whole simulation period, including for spring and neap tides, are shown in Fig. 5. It can be seen that the numerical model results agreed well with measured data, especially at Newport, although there is a $30 \mathrm{~cm}-40 \mathrm{~cm}$ under prediction at the wave crest compared with field data at the Mumbles and the Hinkley Point.

\subsection{Validation of tidal currents}

Comparisons of velocities have also been made to validate the computational accuracy of the EFDC model, with field data being available for validation at sites along the South Wales coast and at Minehead [3-5]. The two sites are referred to as S1 and S2 in Fig.1. Fig. 6 illustrates the comparisons between the numerical model predictions and the observed data, which again indicate that the predicted velocities generally show good agreement with the field data for both the current speed and direction, at both sites, although there are some visible differences at the $91^{\text {st }}$ and $140^{\text {th }}$ hour, with $0.3 \mathrm{~m} / \mathrm{s}$ and 0.2 $\mathrm{m} / \mathrm{s}$ respectively at site $\mathrm{S} 1$. Overall, the predicted results can be considered to have reproduced the field data satisfactorily. The differences between the predicted and field data were calculated and the root mean squared values for the tidal levels and currents were found to be 0.2122 and 0.1857 , respectively.

Tidal stream data given in Admiralty Chart No. 1179 were also used to validate the numerical model predictions for the tidal currents, with comparisons between the numerical results and observed data being shown in Fig. 7 for four sites B, M, Q and U respectively. Site B is located in the outer region of the Bristol Channel and close to the seaward open boundary; sites M and Q are in the middle of the Bristol Channel and site $U$ is very close to the proposed location of the Severn Barrage. The predicted results were in good agreement with the observed data at the four sites, both for the spring and neap tides respectively. In particular, it should be noted that the predicted current speeds and directions at Site U, close to the proposed barrage site, were very close to the observed data for both the spring and neap tides.

From the comparisons between the field data and the numerical model results for the water levels and tidal currents, it can be seen that EFDC model provides a reliable numerical prediction of the hydrodynamics in the Bristol Channel and Severn Estuary for establishing the impact of any proposed renewable energy project. 


\section{MODEL APPLICATIONS}

After model validation for the natural conditions in the estuary, the EFDC model was then used to predict the hydrodynamic processes with the barrage module included, with the aim being to predict the hydrodynamic processes within the basin for a range of scenarios, both with and without the Severn Barrage included. Some of the details analysed in this section include: evaluating the changes in the maximum water levels, the minimum water depths, the maximum tidal currents and the impacts of the barrage on the salinity concentration distributions.

\subsection{Prediction of maximum water levels}

Due to the proposed construction and operation of the Severn Barrage across the Bristol Channel and Severn Estuary, as shown in Fig. 2, the hydrodynamic, sediment transport and water quality characteristics in the basin could be significantly affected by such a structure. The corresponding predicted changes in the maximum water levels for a mean spring tide, both with and without the barrage, are shown in Fig. 8. From these comparisons, it can be seen that there will be a very limited impact on the maximum water levels in the outer region of the Bristol Channel. However, there will be a decrease of about $0.5 \mathrm{~m}$ in the water levels downstream of the barrage; and a significant decrease of between 0.5 and $1 \mathrm{~m}$ in the water levels upstream of the barrage due to the reduction in the fluid flux passing upstream of the structure with the barrage in place. These predicted results indicate that the construction of a barrage would reduce the flood risk in the region upstream of the barrage. For accurate predictions of the flood risk impact on the outer region of the Bristol Channel, then far field boundary conditions out to the Continental Shelf would need to be used.

\subsection{Prediction of minimum water depths}

Because of the relatively high bed elevation upstream of the barrage, the minimum water depth will be significantly affected in these regions by the construction of the Severn Barrage, which further affects the variations in the areas of intertidal zones. Fig. 9 shows a comparison of minimum water depths for the cases without and with the barrage, where it can be seen that there is no noticeable influences in the outer region of the Bristol Channel and downstream of the barrage. However, the effect of the barrage significantly affects the low water levels upstream of the structure. For the current model domain, according to the results shown in Fig. 9, the maximum areas of intertidal zones would be $257.9 \mathrm{~km}^{2}$ and 
$1 \quad 177.4 \mathrm{~km}^{2}$ for the cases without and with the Severn Barrage, respectively. So the loss of the intertidal mudflats would be $80.5 \mathrm{~km}^{2}$ or 8,050 hectares, which would lead to an adverse impact on the ecological system within the estuary. Thus, some management measures need to be implemented to composite for this intertidal habitat loss.

\subsection{Prediction of maximum current speeds}

For the maximum tidal currents it can be seen that they are significantly reduced in the computational domain as a result of the barrage, with a comparison of the maximum tidal currents without and with the barrage being shown in Fig. 10. It can be seen that the maximum velocity is close to $2.4 \mathrm{~m} / \mathrm{s}$ in the middle of the Bristol Channel without the barrage and only $1.2 \mathrm{~m} / \mathrm{s}$ at the same location with the barrage. Hence the maximum velocities in the middle of the Bristol Channel and most regions in the Severn Estuary have been significantly reduced, and by as much as up to $50 \%$ in magnitude in some areas, due to the presence of a barrage. However, it can be also seen from the Fig. 10b that the maximum velocities around the sluice gates and turbines would be much greater than those for the case without the barrage, due to the barrage operation.

\subsection{Prediction of distributions of salinity concentration}

Due to a lack of field data for salinity concentration distributions as the boundary input condition and for model validation, the predictions of distributions of salinity are only considered as preliminary results. However, from the numerical model results it is clear that a barrage will appreciably affect the salinity distribution based on these simulations. In undertaking these simulations, the salinity level was set to 35 ppt along the open seaward boundary when water was flowing from sea into the Bristol Channel and was set as zero at the fresh water inflow source, at the tidal limit, at Gloucester. The initial conditions of salinity concentration were varied gradually from the open sea boundary to Gloucester. In order to obtain steady tidally averaged results, the simulation duration lasted for 250 days, starting at 5:30pm on $20^{\text {th }}$ July, 2001, and lasting up to 5:30pm on $26^{\text {th }}$ March, 2002. The total CPU time for 250 days of simulation was 52.37 hours. Fig. 11 shows the time series of salinity concentrations at a site close to the barrage, which indicates that the model begins to reach tidal steady state after a spin-up period of approximately 220 days. Therefore, the results after 220 days have been used to analyze the distribution of the salinity concentration distributions. 
For the case without a barrage the isohalines at high water at Swansea are shown in Fig. 12 (a), from which it can be seen that the contour lines are parallel with each other, and decreasing gradually from the Bristol Channel to the Severn Estuary. The computed salinity level patterns are similar to those observed patterns for February 1978, as reported by Stephens [22] and Uncles [23]. For convenience, the observed pattern by Stephens is also shown (Fig. 12b). Similarly, the predicted isohalines at low water at Swansea are also compared with the corresponding field data, see Figs. 13 (a) and (b). At low water, some areas along the coastal lines will become dry, with these areas being marked in blue. The observed contour patterns are generally in a west_northwest to east_southeast direction in the most regions in the Bristol Channel at high water and lower water, however, the patterns are changed into a north_northwest to south_southeast direction across the water from Swansea to Minehead at lower water. It can be seen from Figs. 12 (a) and 13 (a) that the changes of the contour patterns have been largely predicted correctly using the current numerical model. The computed salinity patterns have reproduced the field data quite well both at high and low water in the Bristol Channel, as well as in the mouth of the Severn Estuary, except that the computed concentration values are a little higher than the observed values at some sites. The main reason for these differences is thought to be due to the fact that the fresh water inputs were not fully included in this model, with only the River Severn being included. At high water, the predicted salinity concentration distributions are significantly affected by the tidedominated flow, with the corresponding salinity concentrations being higher than those at low water by 1.5 - 2 ppt from the middle region of the Bristol Channel to the upstream region of the Severn Estuary, which is largely consistent with the observed salinity concentration differences between the high and low water (shown in Fig. 12 (b) and Fig. 13 (b)).

Due to the obstruction of the barrage, less water would enter the basin. Therefore, the salinity flux will be affected to some extent and the water upstream of the barrage will become less saline. The computed salinity patterns at high and low water at Swansea are shown for the case with a barrage in Figs. 13 (a) and (b), respectively. At high water, the salinity concentration distribution is largely unaffected by the barrage in the region between the middle of the Bristol Channel and the seaward boundary. However, the salinity concentration is reduced by $1-2$ ppt in the regions downstream and upstream of the barrage. As the River Severn becomes increasingly narrow and meandering upstream of the Severn Bridge and the tide in the Severn Estuary is significantly weakened due to the construction of the barrage, this region will be dominated by the fresh water inputs. The predicted 
results indicate that the salinity concentration value would be reduced by up to 5 ppt between Beachley and Sharpness. At low water, more water with lower salinity concentrations will flow out from upstream to downstream, which will dilute the salinity concentration downstream. The numerical model results show that the salinity concentrations would reduce by $0.5-1 \mathrm{ppt}$ in the middle of the Bristol Channel and downstream and upstream of the barrage. Also, from Figs. 14 (a) and (b) it can be seen that for both high and low water the salinity concentrations upstream of the barrage are about 29 ppt, and decrease gradually upwards along the Severn Estuary, and that the similar salinity concentrations of around 29 ppt can be seen downstream of the barrage. The results indicate that salinity concentrations downstream and upstream of the barrage are under a relatively stable state with a slight variation and that constructing the barrage can reduce the salt intrusion upstream of the barrage. The results shown above were predicted using the 2D EFDC_B model. In order to investigate the 3D effects of the barrage, a 3D model simulation was performed. The model had 5 vertical layers and with its horizontal grid being the same as for the 2D model. The salinity concentration obtained from the 2D model was used as the initial condition for the 3D model. At the filling stage all of the sluice gates and turbines were fully open to allow water to fill the basin, thus the 3D effects of the barrage were relatively small. However, at the generating stage water was allowed only to pass through the turbines, thus the vertical velocity was significantly affected near the turbines. Fig. 15 shows the depth averaged salinity concentration distributions for the 3D case for low water at Swansea for February, 2002. From Fig. 14(b) and Fig. 15, it can be seen that the 2D and 3D models predicted similar salinity distributions for most of the regions, including the Severn Estuary and the region between the middle of the Bristol Channel and the seaward boundary. Near the barrage site, both for the upstream and downstream sides, the 2D and 3D models predicted slightly different salinity levels, with the differences being generally less than 1 ppt. To study the 3D effects of the barrage operation in detail, the salinity concentration distributions in the surface layer and bottom layer around the barrage are shown in Fig 16. At the upper corner on the downstream side of the barrage the salinity level in the bottom layer is higher than in the surface layer. The reason for this phenomenon was caused by an eddy which formed gradually and with the size of the eddy and flow velocity increasing gradually from the bottom to the surface, which indicated that the water in the surface layer had a quicker water exchange than that in the bottom layer in that region. This effect resulted in a reduction in the salinity concentration in the surface layer. Because of the relatively low bed elevation in the region of the lower corner on the downstream side of 
the barrage, many intertidal mudflats appeared at low water (see Fig. 16). Similar hydrodynamic conditions occurred in every vertical layer, thus the salinity concentration distributions in the water column were almost the same in the lower corner downstream of the barrage. Thus it can be concluded that the 2D model can produce similar predictions to the 3D model in most regions. If more details are needed to describe the hydrodynamics and salinity distributions in the region just downstream and upstream of the barrage, then a 3D model should be used.

It can be seen that the reduction in the water volume and the maximum velocity entering the Severn Estuary would influence the transportation of suspended sediments, and the corresponding bacterial and other water quality indicator levels in the water column. The relative impacts on the environmental effects of these water quality parameters are being investigated currently using the refined EFDC model. Meanwhile the potential far field impacts of the Severn Barrage on water levels and flood risk in the areas around the North Wales coast and Irish Sea are also being investigated using a larger domain and the outcome of these research studies will be published shortly.

\section{CONCLUSIONS}

In this study the EFDC model has been refined to include a barrage module for simulating tidal flows through a renewable energy barrage structure, including sluice gates and turbines. The model, including the additional barrage module (EFDC_B), has been used to investigate the impact of the proposed Severn Barrage on the hydrodynamic and salinity processes in the Bristol Channel and Severn Estuary. This model was first validated by comparing the model predicted water levels and tidal currents with field observed data. The results indicated that the model predictions generally agreed well with the field data.

The EFDC_B model was then applied to investigate the hydrodynamic processes in the estuary for a range of scenarios, both with and without the barrage, with the corresponding results showing that with the barrage the maximum water level would be significantly reduced in a large part of the Severn Estuary, especially upstream of the barrage. From the predicted minimum water depths, it has been shown that there would be a mean spring tide loss of $80.5 \mathrm{~km}^{2}$ (or 8,050 hectares) of intertidal habitats due to construction of the barrage. Meanwhile, the peak tidal currents would be considerably reduced, and by as much as a half in some areas along the main channel. 
The comparisons for the predicted salinity concentrations between the cases with and without the barrage indicated that at high water, the salinity concentration would be reduced by 1-2 ppt downstream and upstream of the barrage and in the region near Beachley the value would be reduced by up to 5 ppt, and that at low water, salinity concentrations would be reduced by $0.5-1 \mathrm{ppt}$ in the middle of the Bristol Channel and by 0.5 ppt and $1 \mathrm{ppt}$ downstream and upstream of the barrage, respectively. The predicted results also indicated that the salinity concentration values downstream and upstream of the barrage would be under a relatively stable condition with slight oscillations due to the effect of the barrage.

A comparison between salinity concentration distributions predicted by the 2D and 3D models indicated that they produced similar salinity distributions in the Severn Estuary and the region between the middle of the Bristol Channel and the seaward boundary. Near the barrage site, both on the upstream and downstream sides, the 2D and 3D models predicted slightly different salinity levels, with the difference being generally less than 1 ppt. Hence, in the region near to the barrage site it is preferable to use a 3D model for more detailed and accurate hydrodynamic and solute concentration distributions, as shown in recent studies by Jeffcoate et al. [24]

\section{ACKNOWLEGEMNT}

This work was undertaken as part of the Low Carbon Research Institute Marine Consortium (www.lcri.org.uk). The authors wish to acknowledge the financial support of the Welsh Government, the Higher Education Funding Council for Wales, the Welsh European Funding Office and the European Regional Development Fund Convergence Programme.

\section{REFERENCES}

[1] Falconer, RA., Xia, J., Lin, B., Ahmadian, R, The Severn Barrage and other tidal energy options: hydrodynamic and power output modelling, Springer, Science in China Series E, Technological Sciences. 2009, 52 (11): 3105-3424.

[2] Owen A. A three-dimensional model of the Bristol Channel. Journal of Physical Oceanography 1980; 10: 1290-1302.

[3] Stephens CV. A three-dimensional model for tides and salinity in the Bristol Channel. Continental Shelf Research 1986; 6(4): 531-560. 
1 [4] Uncles RJ, Jordan MB. Measurements of tidal currents and estimated energy fluxes in the Bristol Channel. In: Beven KJ, editor. Mixing and transport in the environment. Chichester, UK: John Wiley; 1984. p. 221-245.

[5] Evans, G.P., Mollowney, B.M., Spoel, N.C, Two-dimensional Modelling of the Bristol Channel, UK. In: Spaulding, M.L. (Ed.), Proceedings of the Conference on Estuarine and Coastal Modeling. 1990, 331-340.

[6] Amin M, Flather RA. Investigation into the possibilities of using Bristol Channel models for tidal predictions. In: Spaulding ML, Cheng RT, editors. Proceedings of the 4th international conference on estuarine and coastal modeling; 1995. p. 41-52.

[7] Xia, J., Falconer, RA., Lin, B., Impact of different tidal renewable energy projects on the hydrodynamic processes in the Severn Estuary, UK, Ocean Modelling. 2010, 86-104.

[8] Xia, J., Falconer, RA., Lin, B., Impact of different operating modes for a Severn Barrage on the tidal power and flood inundation in the Severn Estuary, Applied Energy. 2010, 87 (7): 2374-2391.

[9] Xia, J., Falconer, RA., Lin, B., Hydrodynamic impact of a tidal barrage in the Severn Estuary, UK, Renewable Energy. 2010, 35 (7) 1455-1468.

[10] Ahmadian, R., Falconer, RA., Lin, B., Hydro-environmental modeling of the proposed Severn barrage, Proceedings of the Institution of Civil Engineers, Energy. 2010, 163(3): 107-117.

[11] Hamrick, J.M., A three dimensional environmental fluid dynamics computer code: theoretical and computational aspects. Special Report on Marine Science and Ocean Engineering No. 317. Virginia Institute of Marine Science, The College of William and Mary, Virginia, 1992.

[12] Mellor, G.L., Yamada, T., Development of a turbulence closure model for geophysical fluid problems. Reviews of Geophysics and Space Physics. 1982, 20, 851- 875.

[13] Khangaonkar, T., Z. Yang, C. DeGasperi, and K.Marshall, Modeling Hydrothermal Response of a Reservoir to Modifications at a High Head Dam. Water International. 2005, Volume 30, Number 3, 378-388.

[14] Yang, Z., and J. M. Hamrick., Variational inverse parameter estimation in a cohesive sediment transport model: an adjoint approach. Journal of Geophysical Research. 2003, 108(C2), 3055.

[15] Cerco, C., Tillman, D., and Hagy, JD., Coupling and comparing a spatially- and temporallydetailed eutrophication model with an ecosystem network model: An initial application to Chesapeake Bay. Environmental Modelling and Software. 2010, 25, 562-572. 
[16] Liu, X., Huang, W., Modeling sediment resuspension and transport induced by storm wind in Apalachicola Bay, USA. Environmental Modelling and Software. 2009, 24, 1302-1313.

[17] Shen, J., Boon, J., Kuo, A.Y., A numerical study of a tidal intrusion front and its impact on larval dispersion in the James River estuary, Virginia Estuaries. 1999, 22 (3A), 681-692.

[18] Zou, R., Carter, S., Shoemaker, L., Parker, A., Henry, T., An integrated hydrodynamic and water quality modeling system to support nutrient TMDL development for Wissahickon Creek. Journal of Environmental Engineering. 2006, 132, 555-566.

[19] Bai, S., and W.-S. Lung, Modeling sediment impact on the transport of fecal bacteria. Water Research. 2005, 39, 5232-5240.

[20] Severn Tidal Power Group (STPG), The Severn barrage project: general report, energy paper No. 57. London: Her Majesty’s Stationery Office (HMSO), 1989.

[21] Baker, AC., Tidal Power. The Institute of Engineering and Technology, London, 250, 2006.

[22] Stephens, C.V., A three-dimensional model for tides and salinity in the Bristol Channel. Continental Shelf Research. 1986, Vol. 6. No. 4. pp. 531- 560.

[23] Uncles, R. J., Hydrodynamics of the Bristol Channel. Marine Pollution Bulletin. 1984, Vol. 15, No. 2, pp. 47-53.

[24] Jeffcoate, P., Stansby, P. and Apsley, D., Flow due to multiple jets downstream of a barrage: experiments, 3-D CFD and depth-averaged modelling. Journal of Hydraulic Engineering. 2012, Preview Manuscripts On-line. 


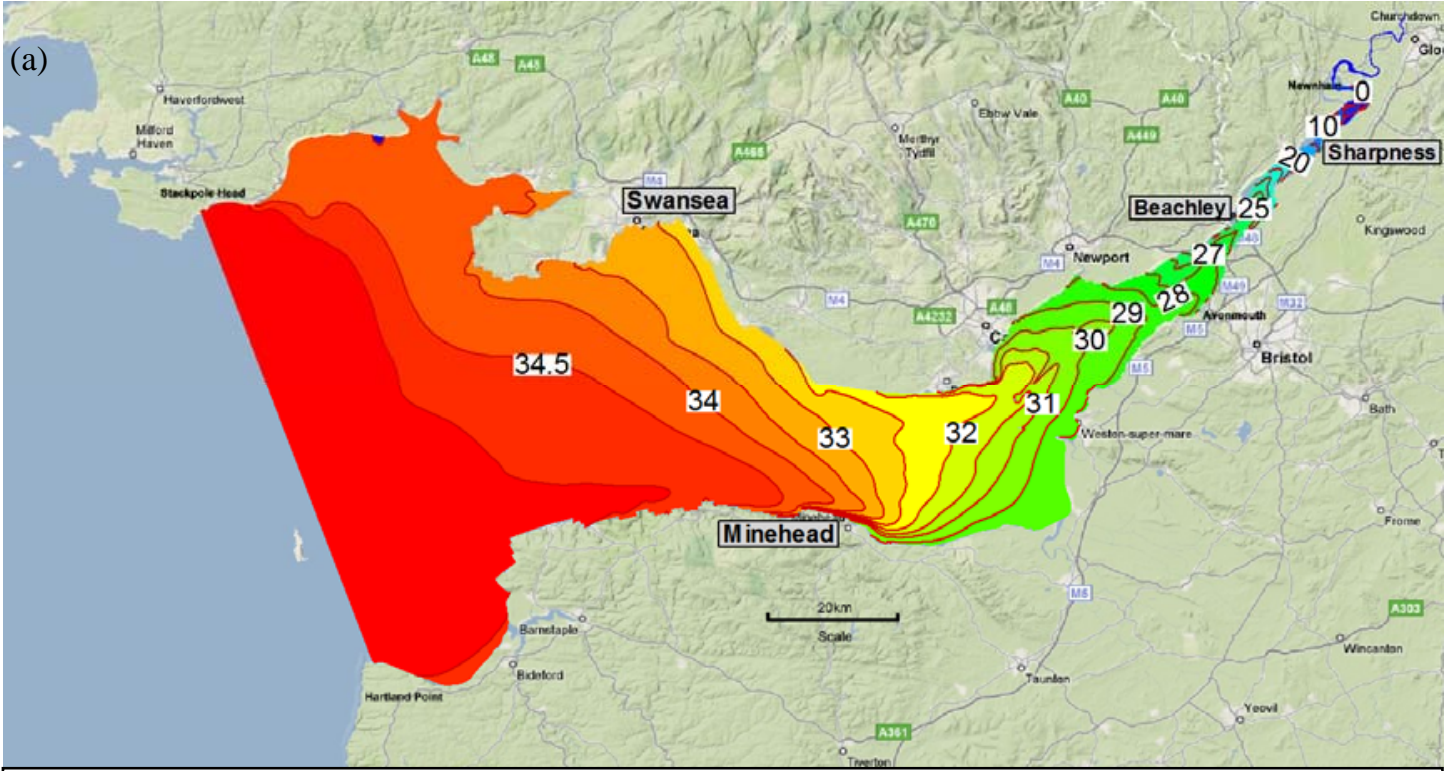

(b)

Fig. 12. Salinity concentration distribution for high water at Swansea: (a) computed results for Feb, 2002, and (b) observed results for Feb, 1978 (Stephens, 1986)

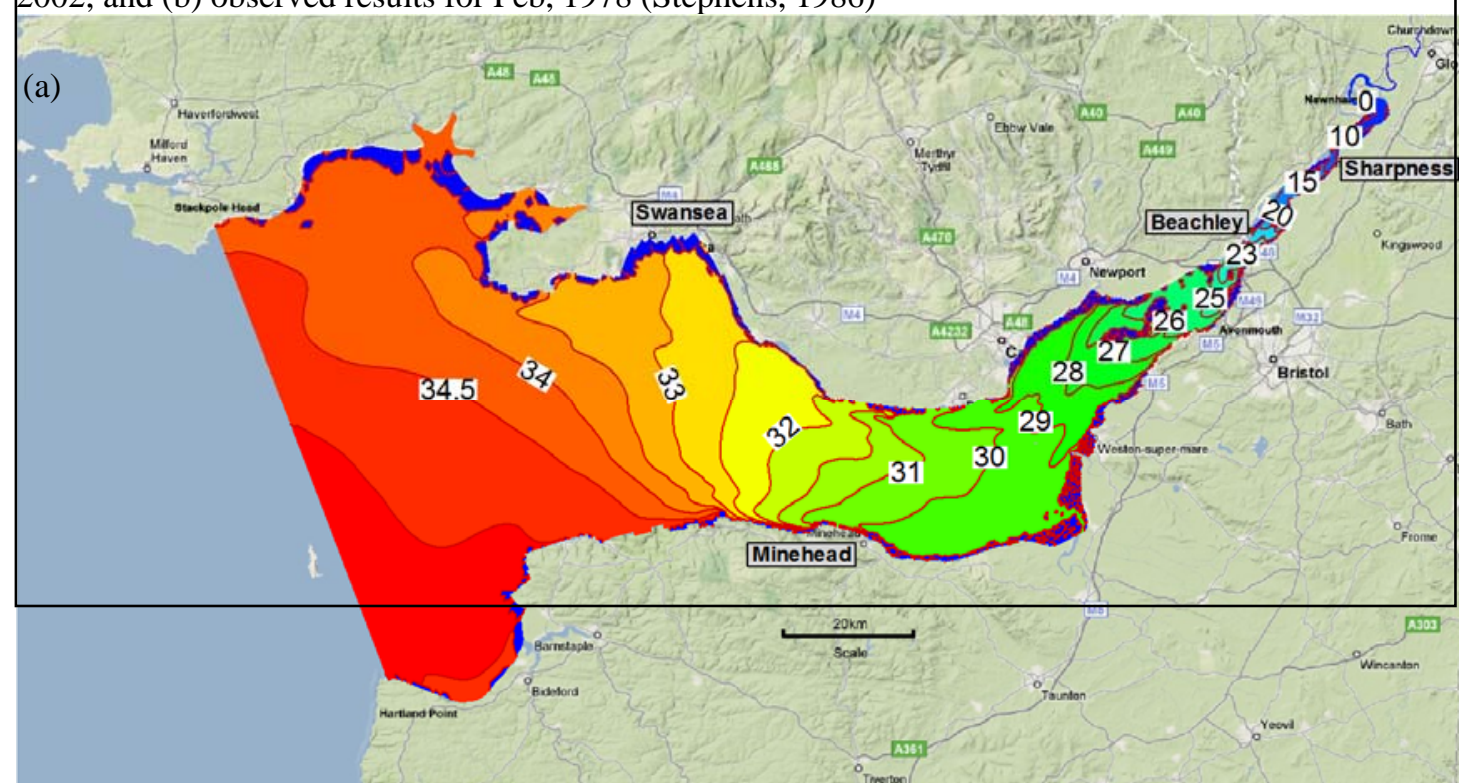




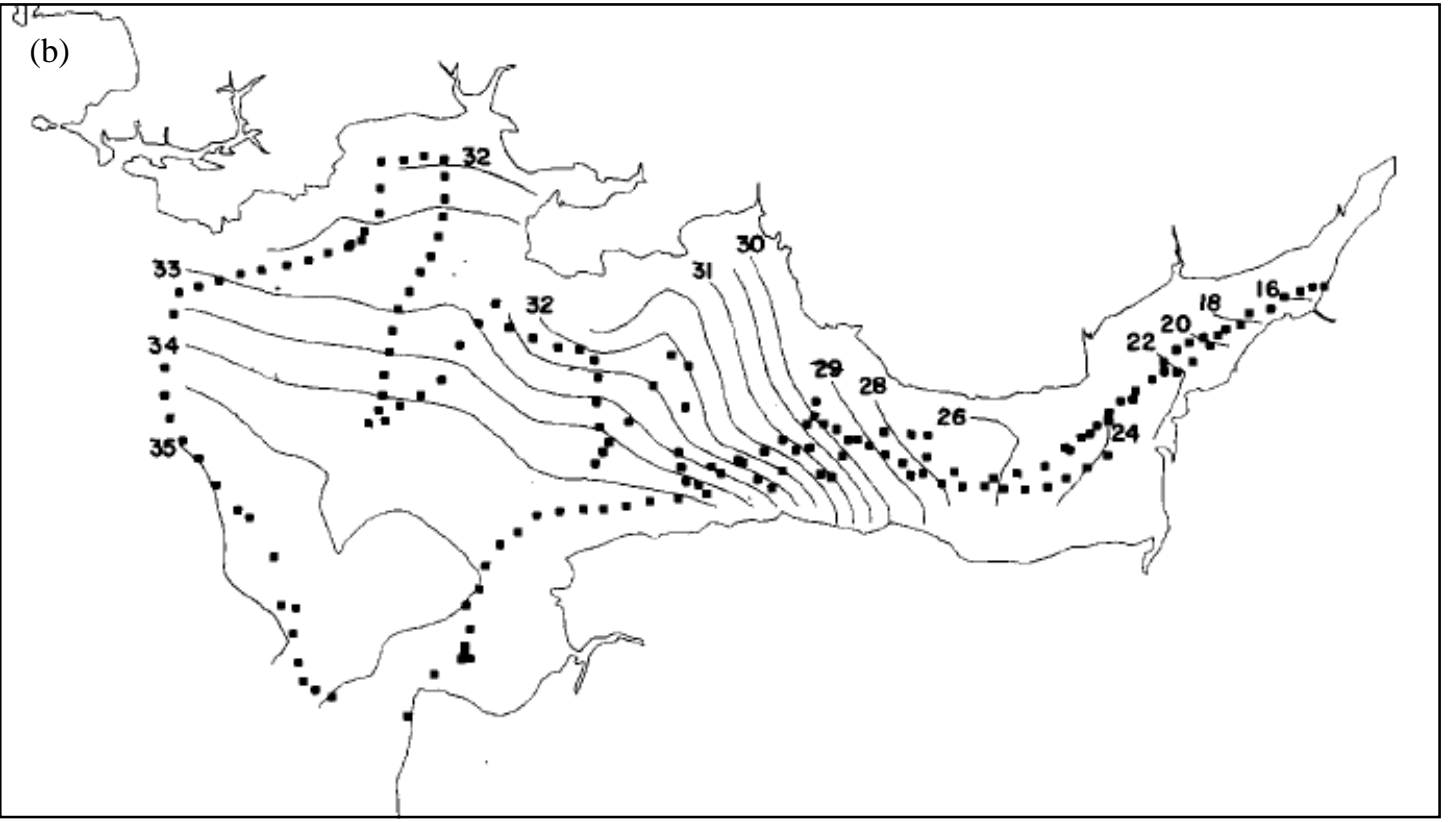

Fig. 13. Salinity concentration distribution for low water at Swansea: (a) computed results for Feb, 2002 and (b) observed results for Feb, 1978 (Stephens, 1986)

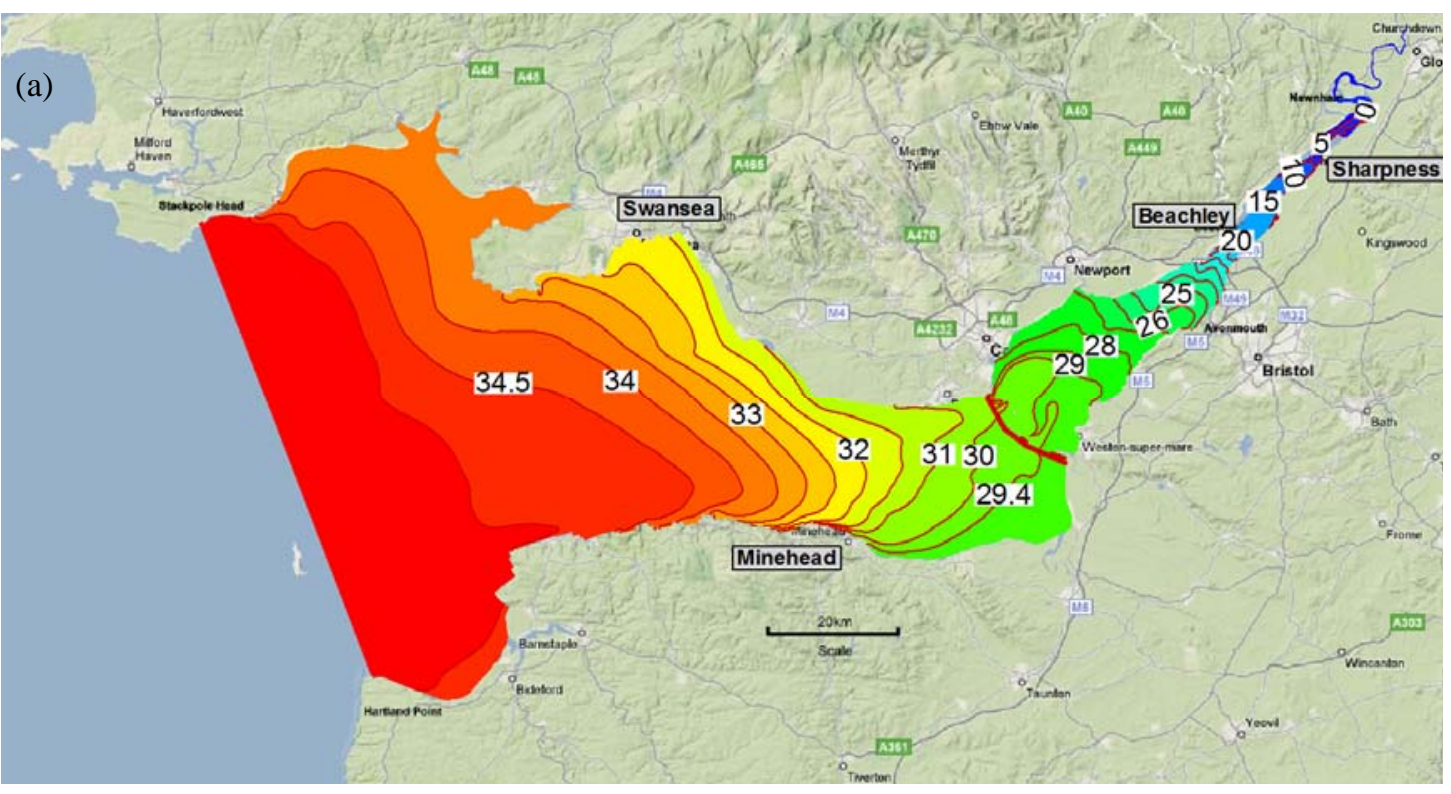




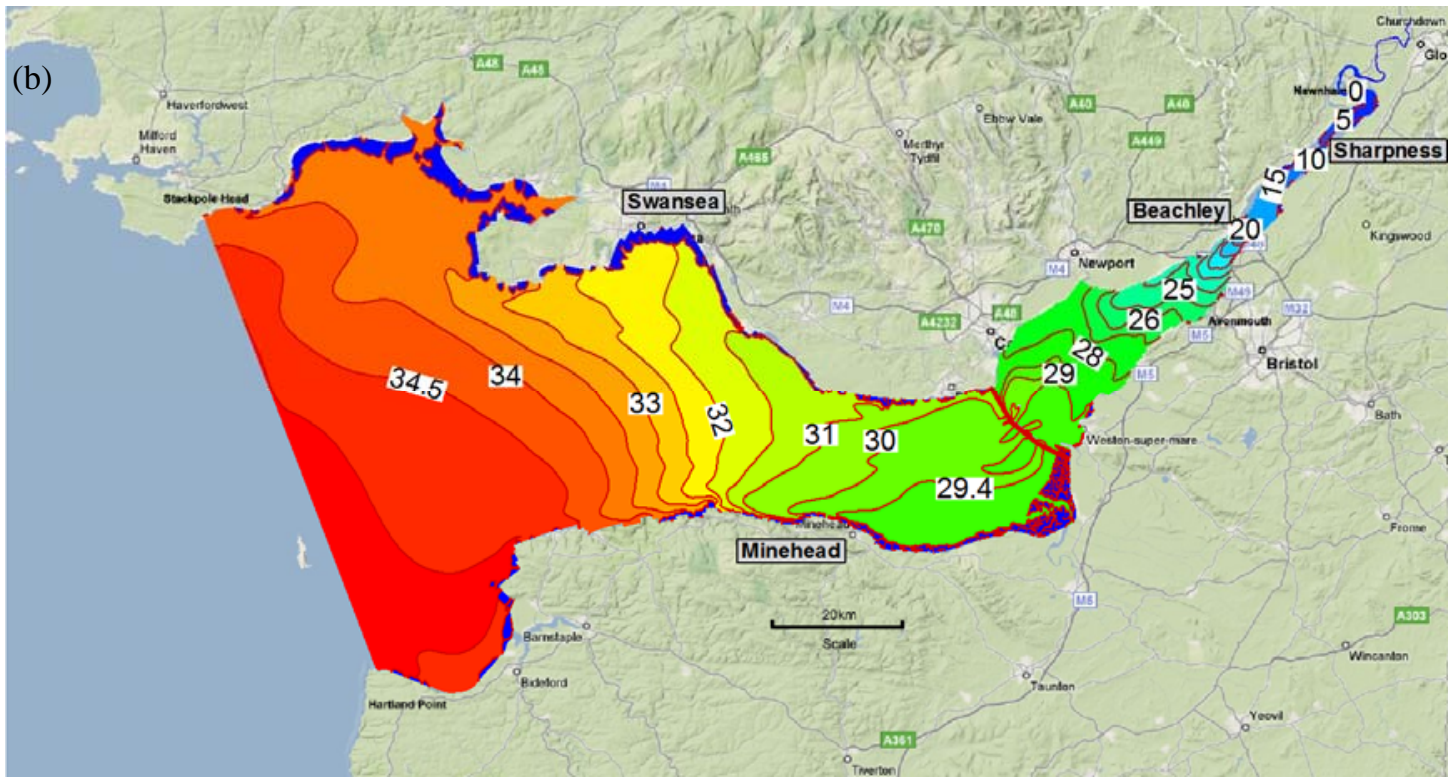

Fig. 14. Predicted salinity concentration distribution for case with a barrage: (a) for high water at Swansea, and (b) for low water at Swansea for Feb, 2002 


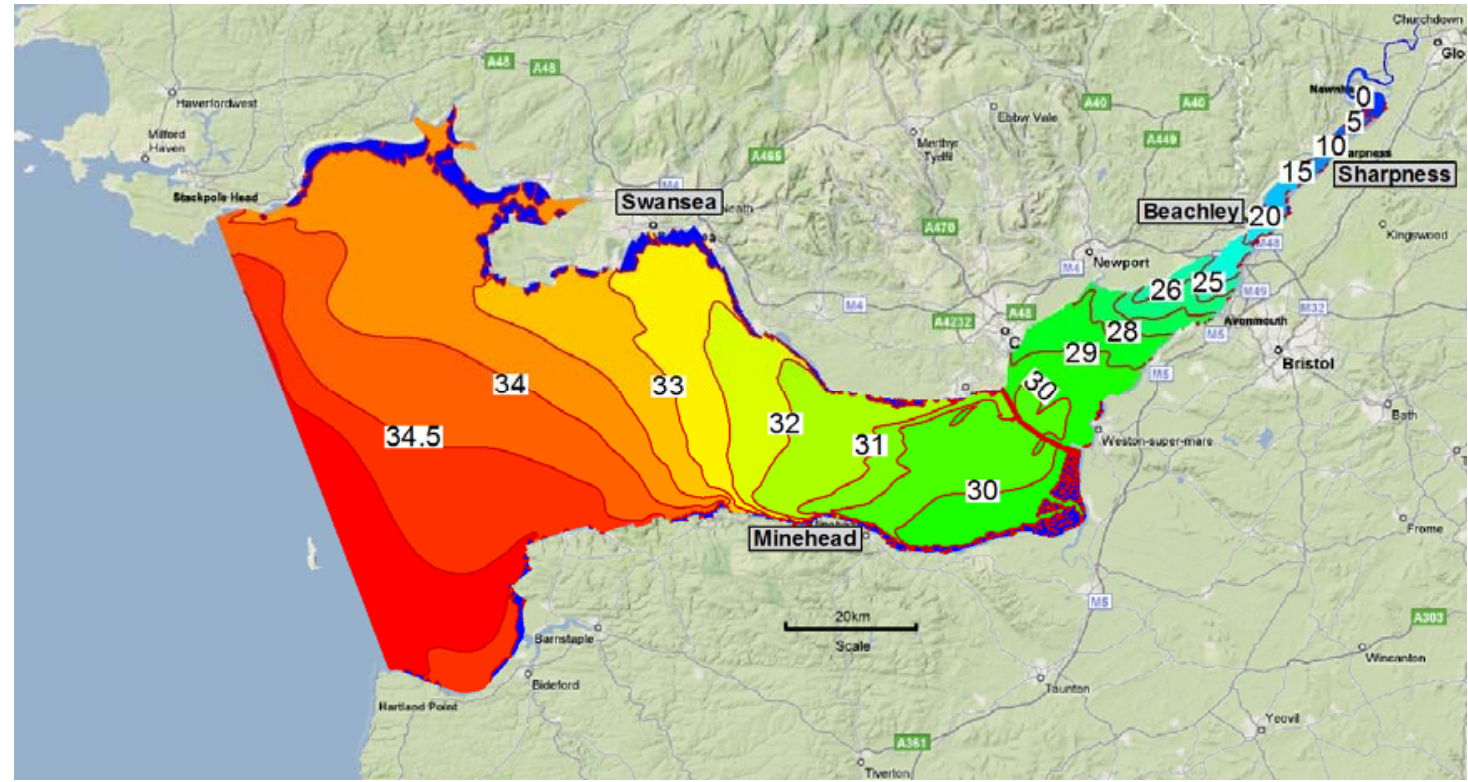

Fig. 15. Model predicted 3D depth average salinity concentration distribution for the case with a barrage for low water at Swansea 


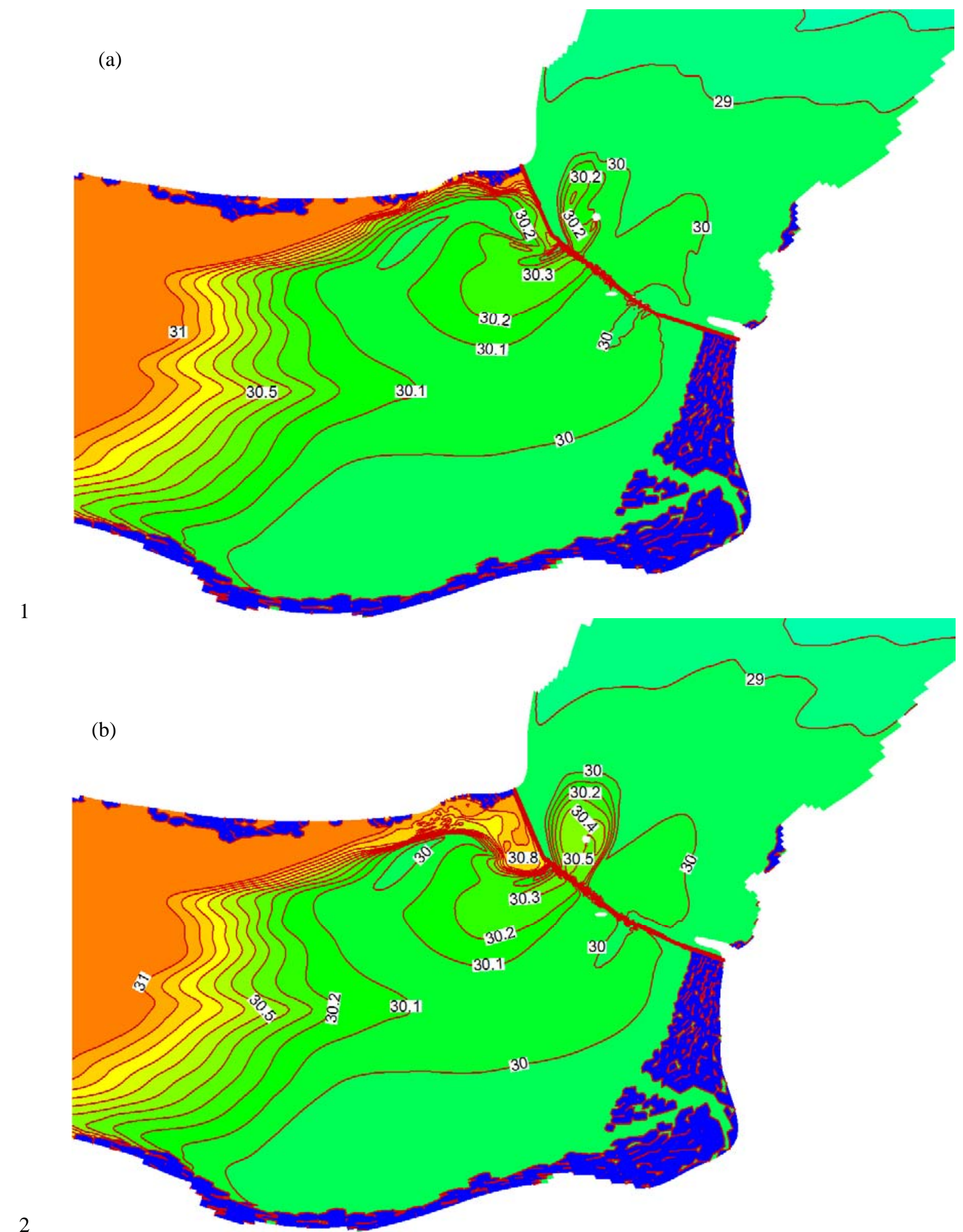

Fig. 16. A comparison between the 3D model predicted salinity concentration distributions at: (a) the surface layer, and (b) bottom layer, for the case with a barrage for low water at Swansea 